\title{
Chronological changes in Epstein-Barr virus genome and subsets of peripheral mononuclear cells in a case of $\mathrm{HLH}$
} \author{
Ichiro Kobayashi ${ }^{1,5^{*}}$ \\ ${ }^{1}$ Department of Pediatrics, Kitami Red Cross Hospital, Kitami, Japan; \\ ${ }^{2}$ Department of Pediatrics, Nagoya University Graduate School of Medicine, Nagoya, Japan; \\ ${ }^{3}$ Department of Pediatrics, Graduate School of Medicine, University of Toyama, Toyama, Japan; \\ ${ }^{4}$ Department of Virology, Nagoya University Graduate School of Medicine, Nagoya, Japan; \\ ${ }^{5}$ Department of Pediatrics, Hokkaido University Graduate School of Medicine, Sapporo, Japan. \\ Email: *ichikobaya@med.hokudai.ac.jp
}

Yukayo Ukeba-Terashita ${ }^{1}$, Yoshinori Saita ${ }^{1}$, Yoshinori Ito ${ }^{2}$, Hirokazu Kanegane ${ }^{3}$, Hiroshi Kimura ${ }^{4}$,

Received 30 April 2011; revised 1 June 2011; accepted 15 July 2011.

\begin{abstract}
Hemophagocytic lymphohistiocytosis (HLH) is a rare disorder characterized by high grade fever, heaptosplenomegaly, lymphadenopathy and cytope- nia in association with hypercytokinemia and mac- rophage activation. Epstein-Barr virus (EBV) is a common cause of HLH particularly in Asian countries. Although EBV usually infects B cells and causes infectious mononucleosis, it is detected predominantly in $\mathrm{CD8}^{+} \mathrm{T}$ cells in EBV-associated HLH. In the present study we found the EBV genome in various lineages of the lymphoid cells including T, B, and natural killer cells in a 14-months-old boy with mild EBV-associated HLH. Furthermore, chronological changes in the copy number of EBV-DNA in each lineage are reported. Profound decrease in the number of peripheral natural killer cells at the early stage could be involved in the development of HLH.
\end{abstract}

Keywords: Epstein-Barr Virus; Hemophagocytic Lymphohistio Cytosis; Natural Killer Cell

\section{INTRODUCTION}

Hemophagocytic lymphohistiocytosis (HLH) is a rare disorder characterized by high grade fever, hepatosplenomegaly, lymphadenopathy and cytopenia in association with hypercytokinemia and macrophage activation [1]. HLH is classified into two clinical entities; primary HLH which develops in inherited diseases such as familial hemophagocytic lymphohistiocytosis (FHL) or primary immunodeficiency, and secondary HLH which develops associated with other acquired disorders such as infection, collagen vascular diseases and malignancy [1]. Sixty percent of the secondary HLH in children is associated with Epstein-Barr virus (EBV) in Japan [2]. Although most cases of EBV-HLH have been reported from Asian countries, reports from other regions have been increasing [3,4]. EBV is a ubiquitous human herpes virus which usually infects $B$ cells and causes self-limiting infectious mononucleosis (IM). On the other hand, persistent or recurrent IM-like disease associated with abnormally high levels of both anti-EBV antibodies and EBV genome is known as chronic active EBV infection (CAEBV) [5]. EBV-associated HLH (EBV-HLH) occurs in association with either CAEBV or a primary infection of the virus [1-5]. Recent reports have demonstrated that EBV infects NK or $\mathrm{CD}^{+}{ }^{+} \mathrm{T}$ cells in CAEBV, whereas it dominantly infects $\mathrm{CD}^{+} \mathrm{T}$ cells in EBV-HLH $[5,6]$. We report here a case of HLH associated with a primary infection of EBV and the chronological changes in EBV-DNA of each lymphoid cell subset.

\section{CASE REPORT}

A previously healthy 14-month-old boy was admitted to our hospital because of fever up to $41^{\circ} \mathrm{C}$ persisting for four days. He was born to non-consanguineous healthy parents and had no history suggesting immunodeficiency or hypersensitivity to mosquito bite. On the third hospital day, cervical lymphadenopathy and hepatosplenomegaly were noted. Laboratory examination showed: white blood cell count $7.89 \times 10^{9} / 1$ (neutrophils $17 \%$, lymphocytes 55\%), hemoglobin $98 \mathrm{~g} / \mathrm{l}$, platelet count $45 \times$ $10^{9} / \mathrm{l}$, aspartate transaminase $543 \mathrm{IU} / \mathrm{l}$, alanine transaminase $204 \mathrm{IU} / \mathrm{l}$, total cholesterol $0.81 \mathrm{~g} / \mathrm{l}$, triglyceride 2.24 g/l, C-reactive protein $115.3 \mathrm{mg} / \mathrm{l}$, ferritin $2090 \mathrm{~g} / \mathrm{l}$. Coagulation study showed: prothrombin time 17.8 seconds, activated partial thromboplastin time 51.8 seconds, fibrinogen $2.66 \mathrm{~g} / \mathrm{l}$ (reference range $2.00 \mathrm{~g} / \mathrm{l}-4.00 \mathrm{~g} / \mathrm{l}$ ) and fibrin degradation products $93.9 \mathrm{~g} / \mathrm{ml}(<10 \mathrm{~g} / \mathrm{ml})$, sug- 
gesting disseminated intravascular coagulation (DIC). NK cell activity and a serum soluble CD25 was $14 \%$ (normal; 18\% - 45\%) and 10,300 U/ml (normal < 520 $\mathrm{U} / \mathrm{ml}$ ), respectively. Although hemophagocytosis was not evident in his bone marrow, seven of the eight items of HLH criteria by Histiocyte Society were fulfilled [1]. Nafamostat mesilate was administered for DIC. Because mild dilatation of coronary artery with a high echogenicity of the arterial wall similar to that observed in Kawasaki disease was detected by echocardiography on the 7th day of hospitalization despite slight improvement of both clinical and laboratory findings, high-dose intravenous immunoglobulin (HD-IVIG) therapy ( $2 \mathrm{~g} / \mathrm{kg}$ ) was started. Serological test for EBV before HD-IVIG therapy showed IgG antibody to viral capsid antigen (VCA) $1: 160$, IgG antibody to early antigen $1: 20$, but negative for IgG antibody to EBV nuclear antigen (EBNA) suggesting a primary infection of EBV. Because his clinical and laboratory findings rapidly improved, no further therapy was performed.

Flow cytometric analysis of his peripheral blood at the onset of HLH demonstrated a high level of CD8 ${ }^{+} \mathrm{HLA}-$ $\mathrm{DR}^{+}$cells, whereas the number of $\mathrm{CD} 19^{+}, \mathrm{CD} 20^{+}, \mathrm{CD}^{+} 6^{+}$, $\mathrm{CD}_{16}{ }^{+}$, and $\mathrm{CD}_{57}{ }^{+}$cells was low (Table 1). The number of $\mathrm{CD}^{+} \mathrm{HLA}^{-\mathrm{DR}^{+}}$cells declined in 20 days which was associated with recovery of $\mathrm{CD} 16^{+}$or $\mathrm{CD} 57^{+}$cells. The ratio of each subset has returned to normal ranges 3 months after the onset.

The copy number of EBV-DNA was analyzed by a real-time polymerase chain reaction after separation of his peripheral blood mononuclear cells (PBMC) into $\mathrm{CD} 19^{+}, \mathrm{CD} 3, \mathrm{CD}^{+}, \mathrm{CD}^{+}, \mathrm{CD} 6^{+}$and $56^{+}$cells by an immunobeads method (DynaBeads; Dynal A/S, Oslo, Norway) as previously reported [7]. DNA was extracted

Table 1. Flow cytometric analyses of the peripheral mononuclear cells.

\begin{tabular}{ccccc}
\hline Date & Apr 5 & Apr 25 & Jul 11 & Nov 6 \\
\hline $\begin{array}{c}\text { Absolute number } \\
\text { of PBMC }\left(/ \mathrm{mm}^{3}\right)\end{array}$ & 3666 & 3846 & 3872 & 5728 \\
CD4 & $19.2 \%$ & $41.6 \%$ & $44.1 \%$ & $36.4 \%$ \\
CD8 & $70.7 \%$ & $40.6 \%$ & $38.7 \%$ & $34.0 \%$ \\
CD8×HLA-DR & $56.7 \%$ & $17.7 \%$ & $11.2 \%$ & $8.9 \%$ \\
CD16 & $2.3 \%$ & $17.2 \%$ & $12.2 \%$ & $20.0 \%$ \\
CD56 & $1.4 \%$ & ND & $6.5 \%$ & $14.9 \%$ \\
CD57 & $4.4 \%$ & $7.6 \%$ & $6.6 \%$ & $12.2 \%$ \\
CD19 & $0.9 \%$ & $0.7 \%$ & $12.7 \%$ & $18.2 \%$ \\
CD20 & $1.2 \%$ & $0.6 \%$ & $9.2 \%$ & $12.9 \%$ \\
\hline
\end{tabular}

Abbreviation: PBMC, peripheral mononuclear cells; ND, not done. from $2 \times 10^{6}$ PBMC using a QIAmp Blood Kit (Qiagen, Hilden, Germany). A real-time quantitative PCR assay with a fluorogenic probe was performed using TaqMan PCR kit (PE Applied Biosystems, Foster City, CA). The amount of EBV-DNA was calculated as the number of virus copies per microgram PBMC DNA. The copy number of EBV-DNA was extremely high at the onset in all of $\mathrm{CD} 19^{+}, \mathrm{CD} 3, \mathrm{CD} 4^{+}, \mathrm{CD} 8^{+}, \mathrm{CD} 16^{+}$and $56^{+}$cells. A high level infection with $\mathrm{CD}_{16}{ }^{+}$or $56^{+}$cells persisted at least for five months, although the copy number of the viral DNA declined with the clinical improvement (Table 2). One year after the onset EBV-DNA was detectable only in $\mathrm{CD}_{19^{+}}$cells at a latent infection level comparable to normal individuals with a past infection of the virus.

After the recovery from HLH, he has not shown any IM-like symptoms or abnormal laboratory findings during 2 years of follow up. IgG antibody to EBV early antigen disappeared soon, whereas serum levels of IgG antibodies to VCA and EBNA gradually elevated to $1: 1280$ and $1: 40$ in 5 months, respectively. NK activity restored to $45 \%$. No mutation was detected in either $S H 2 D 1 A$ or XIAP gene.

\section{DISCUSSION}

In the present study, we analyzed chronological changes of EBV-DNA in each subset of PBMC in a case of EBV-HLH. From his clinical course and the profile of anti-EBV antibodies, HLH was likely associated with a primary infection of EBV rather than CAEBV. Although coronary lesion was transiently observed, the diagnostic criteria for Kawasaki disease was not fulfilled [8]. In addition to vasculitis such as Kawasaki disease, coronary lesions develop in association with infection of the virus to the endothelial cells in CAEBV or with systemic inflammation as observed in systemic-onset juvenile idiopathic arthritis $[9,10]$.

Our case showed increased number of peripheral CD8 ${ }^{+} \mathrm{HLA}^{-\mathrm{DR}^{+}}$cells and a decrease in both the number and the activity of NK cells at the diagnosis, which is consistent with the previous reports of EBV-HLH [11].

Table 2. Chronological changes of EBV-DNA (copies/g DNA) in each subset.

\begin{tabular}{ccccccc}
\hline Date & Apr 5 & Apr 25 & Jun 7 & Sep5 & Jan 9 & Apr 16, 2008 \\
\hline PBMC & $110 \times 10^{4}$ & $4.77 \times 10^{4}$ & 269 & 858 & 54 & 86 \\
CD3 & $17.9 \times 10^{4}$ & $3.46 \times 10^{4}$ & 20 & 823 & ND & ND \\
CD4 & $1.22 \times 10^{4}$ & $0.74 \times 10^{4}$ & 17 & 249 & ND & ND \\
CD8 & $40.2 \times 10^{4}$ & $3.55 \times 10^{4}$ & 0 & 527 & ND & ND \\
CD16 & ND & $5.14 \times 10^{4}$ & 1483 & 311 & 99 & ND \\
CD56 & $97.8 \times 10^{4}$ & $5.13 \times 10^{4}$ & 1295 & 1769 & ND & ND \\
CD19 & $13.9 \times 10^{4}$ & $2.16 \times 10^{4}$ & 119 & 932 & 173 & 508 \\
\hline
\end{tabular}

Abbreviation: PBMC, peripheral mononuclear cells; ND, not done. 
The dominant population of EBV-infected cells is reported to be $\mathrm{CD}^{+} \mathrm{T}$ cells in EBV-HLH, whereas the major targets of EBV in CAEBV are $\mathrm{CD} 4^{+} \mathrm{T}$ cells or $\mathrm{NK}$ cells [5-7]. EBV-infected CD8 ${ }^{+}$Tcells are activated and produce cytokines such as IFN- $\gamma, \mathrm{TNF}-\alpha$ and interleukin-6, which activate macrophages and endothelial cells resulting in hemophagocytosis, DIC, and multiorgan failure $[1,5,12]$. NK cells, as well as EBV-specific cytotoxic T cells (CTL), play a critical role in the elimination of EBV-infected cells [1]. This is supported by the fact that the functional defects in cytotoxic activity of CTL and NK cells such as X-linked lymphoproliferative syndrome and FHL predispose for EBV-HLH [1]. In acute IM the number of NK cells, although it usually increases, is inversely correlated with the severity of the disease [13]. Thus, the numerical defect of NK cells as observed in our case could cause the development of EBV-HLH or severe IM. Our case showed subsequent recovery of both $\mathrm{NK}$ activity and the number of $\mathrm{CD} 16^{+}$, $56^{+}$or $57^{+}$cells as well as decline in $\mathrm{CD}^{+} \mathrm{HLA}^{-\mathrm{DR}^{+}}$ cells, which was associated with clinical improvement. Furthermore, no mutation was detected in causative genes of XLP such as $S H 2 D A$ or XIAP gene. Thus, although mutations of other FHL-related genes have not been tested, the numerical and functional abnormality was unlikely to be intrinsic to his NK cells. Of note was the finding that high levels of EBV-DNA was detected in $\mathrm{CD}_{16}{ }^{+}$and $56^{+}$cells, in addition to $\mathrm{T}$ and $\mathrm{B}$ cells, despite the decreased number of the subsets in our case. Although other methods such as in situ hybridization and immunohistochemistry were not performed, a high level of infection in CD $16^{+}$and $56^{+}$cells was confirmed by serial examination for several months. The copy number of EBV-DNA in PBMC of our case was comparable to that in previously reported cases of EBV-HLH, CAEBV and post-transplantational lymphoproliferative disorder [14]. Although EBV-HLH has a tendency to have larger viral burdens than acute phase of IM, it is difficult to differentiate between these two diseases simply by viral load in whole PBMC [15]. The copy number of EBVDNA gradually declined in all of the subsets and was finally detectable in B cells only at a latency level one year after the onset of the disease. These findings are in contrast to NK cell-type CAEBV or NK cell lymphoma which shows a clonal expansion of EBV-infected NK cells [5]. It is known that EBV is able to infect NK cells at an early stage of IM, although the precise mechanisms of infection remain unclear [16]. As well, EBV genome is also detected in both $\mathrm{NK}$ and $\mathrm{B}$ cells under some conditions such as EBV-HLH but usually at a lower level than $\mathrm{CD}^{+} \mathrm{T}$ cells [6]. Isobe et al have reported that in vitro infection of EBV induces apoptosis of NK cells [17]. Thus, it is possible that the infection by EBV in- duced apoptosis of NK cells in vivo and allowed unregulated activation of EBV-infected $\mathrm{CD}^{+} \mathrm{T}$ cells. Decreased number of peripheral B cells in association with HLH as observed in our case has also been reported [18]. Imashuku et al have demonstrated depletion of B cells in the spleen of the patients with HLH and suggested involvement of cytokines produced by activated $\mathrm{T}$ or NK cells and/or Fas-FasL-mediated apoptosis [18].

Although our case showed both clinical and laboratory improvement before the commencement of HDIVIG therapy suggesting self-limiting nature, it is possible that the therapy accelerated the improvement by its anti-inflammatory mechanism [19]. Further studies are required to clarify the mechanisms of the decrease in the number of peripheral NK cells in EBV-HLH without underlying primary immunodeficiencies or FHL.

In conclusion, EBV infected various subsets of PBMC including NK cells in a case of HLH associated with a primary infection of EBV. EBV genome gradually declined in association with his clinical improvement and was finally detectable in only B cells at a latency level. Transient decrease in NK cells could be involved in the development of EBV-HLH in our case.

\section{REFERENCES}

[1] Henter, J.-I., Horne, A.C., Aricó, M., et al. (2007) HLH2004: Diagnostic and therapeutic guidelines for hemophagocytic lymphohistiocytosis. Pediatric Blood \& Cancer, 48, 124-131. doi:10.1002/pbc.21039

[2] Ishii, E., Ohga, S., Imashuku, S., et al. (2007) Nationwide survey of hemophagocytic lymphohistiocytosis in Japan. International Journal of Hematology, 86, 58-65. doi:10.1532/IJH97.07012

[3] Beutel, K., Gross-Wieltsch, U., Wiesel, T., Zur Stadt, U., Janka, G. and Wagner, H.-J. (2009) Infection of T lymphocytes in Epstein-Barr virus-associated hemophagocytic lymphohistiocytosis in children of non-Asian origin. Pediatric Blood \& Cancer, 53, 184-190.

[4] Sonke, G.S., Ludwig, I., Van Oosten, H., et al. (2008) Poor utcomes of chronic active Epstein-Barr virus infection and hemophagocytic lymphohistiocytosis in non-Japanese adult patients. Clinical Infectious Diseases, 47, 105-108. doi:10.1086/588790

[5] Kimura, H. (2006) Pathogenesis of chronic active Epstein-Barr virus infection: Is this an infectious disease, lymphoproliferative disorder, or immunodeficiency? $R e$ views in Medical Virology, 16, 251-261. doi:10.1002/rmv.505

[6] Kasahara, Y., Yachie, A., Takei, K., et al. (2001) Differential cellular target of Epstein-Barr virus (EBV) infection between acute EBV-associated hemophagocytic lymphohistiocytosis and chronic active EBV infection. Blood, 98, 1882-1888. doi:10.1182/blood.V98.6.1882

[7] Kimura, H., Hoshino, Y., Kanegane, H., et al. (2001) Clinical and virological characteristics of chronic active Epstein-Barr virus infection. Blood, 98, 280-286. doi:10.1182/blood.V98.2.280 
[8] Ayusawa, M., Sonobe, T., Uemura, S., et al., (2005) Revision of diagnostic guidelines for Kawasaki disease (the 5th revised edition). Pediatrics International, 47, 232-234. doi:10.1111/j.1442-200x.2005.02033.x

[9] Kikuta, H., Sakiyama, Y., Matsumoto. S., et al. (1993) Detection of Epstein-Barr virus DNA in cardiac and aortic tissues from chronic, active Epstein-Barr virus infection associated with Kawasaki disease-like coronary artery aneurysms. Journal of Pediatrics, 123, 90-92. doi:10.1016/S0022-3476(05)81546-X

[10] Binstadt, B.A., Levine, J.C., Nigrovic, P.A., et al. (2005) Coronary artery dilation among patients presenting with systemic-onset juvenile idiopathic arthritis. Pediatrics, 116, e89-e93. doi:10.1542/peds.2004-2190

[11] Kogawa, K., Lee, S.M., Vilanueva, J., et al. (2002) Perforin expression in cytotoxic lymphocytes from patients with hemophagocytic lymphohistiocytosis and their family members. Blood, 99, 61-66. doi:10.1182/blood.V99.1.61

[12] Chuang, H.-C., Hsie, W.-C., Wang, H.-C., et al. (2005) Epstein-Barr virus LMP1 inhibits the expression of SAP gene and upregulates Th1 cytokines in the pathogenesis of hemophagocytic syndrome. Blood, 106, 3090-3096. doi:10.1182/blood-2005-04-1406

[13] Williams, H., McAulay, K., Macsween, K.F., et al. (2005) The immune response to primary EBV infection: A role for natural killer cells. British Journal of Haematology, 129, 266-274. doi:10.1111/j.1365-2141.2005.05452.x

[14] Kimura, H., Morita, M., Yabuta, Y., et al. (1999) Quantitative analysis of Epstein-Barr virus load by using realtime PCR assay. Journal of Clinical Microbiology, 37, 132.

[15] Kimura, H., Hoshino, Y., Hara, S., et al. (2002) Viral load in Epstein-Barr virus-associated hemophagocytic syndrome. Microbiology and Immunology, 46, 579-582.

[16] Trempat, P., Tabiasco, J., Andre, P., et al. (2002) Evidence for early infection of nonneoplastic natural killer cells by Epstein-Barr virus. Journal of Virology, 76, 11139-11142. doi:10.1128/JVI.76.21.11139-11142.2002

[17] Isobe, Y., Sugimoto, K., Yang, L, et al. (2004) EpsteinBarr virus infection of human natural killer cell lines and peripheral blood natural killer cells. Cancer Research, 64, 2167-2174.

[18] Imashuku, S., Obayashi, M., Hosoi, G., et al. (2000) Splenectomy in haemophagocytosis: Report of histopathological changes with CD19; B-cell depletion and therapeutic results. British Journal of Haematology, 108, 505-510. doi:10.1046/j.1365-2141.2000.01904.x

[19] Nimmerjahn, F. and Ravetch, J.V. (2008) Anti-inflammatory actions of intravenous immunoglobulin. Annual Review of Immunology, 26, 513-533. doi:10.1146/annurev.immunol.26.021607.090232 